\title{
Quantification of Arsenic, Cadmium, Mercury and Lead in Pineapple: Method Development, Validation and Evaluation of In-House Reference Materials
}

\author{
Diego A. Garzón, ${ }^{\circledR a}$ Diego A. Ahumada, ${ }^{b}$ Johanna P. Abella Gamba, ${ }^{b}$ Jesus Ágreda ${ }^{\circledR a}$ \\ and Elianna Castillo*,a \\ ${ }^{a}$ Departamento de Química, Universidad Nacional de Colombia, \\ Avenue 50 No. 26-55 Int. 2, 11001 Bogota, Colombia \\ ${ }^{b}$ Subdirección de Metrología Química y Biomedicina, Instituto Nacional de Metrología de Colombia, \\ Av. Cra 50 No 26-55 Int. 2 CAN, 111321 Bogota, Colombia
}

\begin{abstract}
A method for quantification of arsenic, cadmium, mercury, and lead in pineapple using inductively coupled plasma-mass spectrometry (ICP-MS) was developed, validated, and used to test the homogeneity and stability of in-house reference materials. The method was tested at the regulation levels given by the Food and Agriculture Organization of the United Nations (FAO, $100 \mu \mathrm{g} \mathrm{kg}^{-1}$ ). The mineralization conditions of the samples, in a microwave oven, were improved throughout the study of $\mathrm{HNO}_{3}$ and $\mathrm{H}_{2} \mathrm{O}_{2}$ concentrations, sample weight, time, and temperatures. The calibration was made by a gravimetric standard addition method with internal standard correction. The validation parameters were accuracy (trueness as recovery, between $97-112 \%$, and precision as repeatability, below 12\%), limits of detection (As 14.2, Cd 1.5, $\mathrm{Hg} 21.9$, and Pb $5.4 \mu \mathrm{g} \mathrm{kg}^{-1}$ measured in pineapple), linearity and selectivity. The in-house material was lyophilized or dried in an oven. The best way to dry it was by the oven process because it has the lowest uncertainty.
\end{abstract}

Keywords: pineapple, gravimetric standard addition, toxic elements, ICP-MS, in-house reference material

\section{Introduction}

The pineapple is one of the main fruits exported by Panama, Brazil, Costa Rica, Colombia, and other Latin American countries. ${ }^{1}$ This fruit has become one of the most attractive South America agricultural products in the international market. ${ }^{2}$ However, the growing concerns over food security and more considerable attention on healthy eating, particularly the efforts to avoid toxic elements (as $\mathrm{As}, \mathrm{Cd}, \mathrm{Hg}$, and $\mathrm{Pb}$ ) in human diets, have led to imposing requirements for food that is intended to be exported. This means that a greater focus must be put on the official methods and reference materials for the quantification of those toxic elements in food, ${ }^{3-7}$ in order to maintain an alimentary control and satisfying the requirements of the countries where the products will be exported.

The determination of $\mathrm{As}, \mathrm{Cd}, \mathrm{Hg}$, and $\mathrm{Pb}$ in food is a well-documented topic ${ }^{8-11}$ due to the impact that these elements have on the health of human beings. The analytical methods used for quantification of these toxic elements

*e-mail: ecastillo@unal.edu.co in food are numerous and based on elemental techniques such as graphite furnace atomic absorption (GFAA), ${ }^{12}$ cold vapor atomic absorption (CVAA), ${ }^{3}$ high-resolution continuum-source atomic absorption spectroscopy $(\text { HR-CS AAS) })^{13}$ and inductively coupled plasma with optical emission (ICP OES) or mass spectrometry detection (ICP-MS). ${ }^{89}$ Also, a significant quantity of options is found in the electrochemical field. ${ }^{14}$ These methods have many advantages, such as high sensitivity and accuracy, and some have been adopted by regulatory agencies. Unfortunately, in these methods, the matrix effects are always a problem.

The matrix effects, classified as translational and rotational, ${ }^{13}$ must always be considered in the development of any method of quantification. In ICP-MS, when the background signal is low, the translational matrix effects can be attributed to the spectral interferences, which could be reduced by the clean-up stages and collision or reaction cell. ${ }^{15}$ The standard addition method (SAM) is effective in reducing the rotational matrix effects and has been applied widely to many difficult matrices and analytes. ${ }^{16} \mathrm{SAM}$, with a gravimetric preparation, increases design flexibility and accuracy. ${ }^{17}$ This method can be used to validate analytical 
procedures in complex matrices when there are no other available standardized methodologies (isotopic dilution or bracketing with internal standard) and when there are no available certified reference materials (CRM).

National Metrology Institutes (NMIs) offer CRM, but not always they can supply the matrices and analytes required. Therefore, the International Standard Organization (ISO) through Committee on Reference Materials (ISO/ REMCO) has developed guidelines to produce in-house reference materials (iHRM) or quality control materials (QCM) as an alternative to the CRM which are required by the validation and quality control procedures. The guide ISO 80:2014 ${ }^{18}$ describes some considerations to prepare iHRM in laboratories and their use for the quality control. ${ }^{19-21}$ The guide ISO 35:201722 explains the assessment of homogeneity, stability, and characterization for reference materials. An iHRM is usually developed when the matrices or reference levels of commercially available CRMs do not closely match the samples to be analyzed or when a sample supply is desired to be available for many years.

Considering the previous facts, this work presents the development and validation of a method for the quantification of $\mathrm{As}, \mathrm{Cd}, \mathrm{Hg}$, and $\mathrm{Pb}$ in pineapple at the intra-laboratory level and using a simple blind procedure. The method includes an improved microwave digestion process, respect to the AOAC $2015.01 .^{23}$ The improvement was achieved throughout a Plackett-Burman experimental design (PB). ICP-MS with standard gravimetric addition and internal standard (IS) correction was used for quantification. ${ }^{24}$ Additionally, and as far as we know, there are no CRM of pineapple available in the common market. Then, a pineapple in-house reference material will be useful for the analytical laboratories involved in the quantification of $\mathrm{As}, \mathrm{Cd}, \mathrm{Hg}$, and $\mathrm{Pb}$ in pineapple. Trying to supply this kind of material, we have prepared two in-house reference materials. The homogeneity and stability of these materials were tested using the developed method for the quantification of $\mathrm{As}, \mathrm{Cd}, \mathrm{Hg}$, and $\mathrm{Pb}$ in pineapple.

\section{Experimental}

\section{Samples and reagents}

All single analyte stock solutions (As $987.3 \mathrm{mg} \mathrm{kg}^{-1}, \mathrm{Cd}$ $989.5 \mathrm{mg} \mathrm{kg}^{-1}$, $\mathrm{Hg} 951.9 \mathrm{mg} \mathrm{kg}^{-1}$ and $\mathrm{Pb} 992.1 \mathrm{mg} \mathrm{kg}^{-1}$ ) were certified by National Institute of Standards and Technology (Gaithersburg, USA), and the National Metrology Institute of Slovak (Bratislava, Slovak). The internal standards (Rh $999 \mathrm{mg} \mathrm{kg}^{-1}$, Tl $1000 \mathrm{mg} \mathrm{kg}^{-1}$ and $\mathrm{U} 9.80 \mathrm{mg} \mathrm{kg}^{-1}$ ), Au standard solution (1000 mg kg-1), $\mathrm{H}_{2} \mathrm{O}_{2}(30 \% \mathrm{~m} / \mathrm{m})$ and $\mathrm{HNO}_{3}(69 \% \mathrm{~m} / \mathrm{m})$ were bought from Sigma-Aldrich
(St. Louis, USA) and Merck Chemicals (Darmstadt, Germany). The $\mathrm{HNO}_{3}$ used was purified by sub-boiling distillation. A stock working standard solution of $10 \mathrm{mg} \mathrm{kg}^{-1}$ for each element was prepared by weighing $1 \mathrm{~g}$ of each stock solution and completing to $100 \mathrm{~g}$ with $2 \%(\mathrm{~m} / \mathrm{m}) \mathrm{HNO}_{3}$. A mixed internal standard solution $10 \mu \mathrm{g} \mathrm{kg}^{-1}$ for $\mathrm{Rh}, \mathrm{Tl}$, and $\mathrm{U}$ was prepared in the same way as the stock. Ultra-pure water (conductivity $\leq 18 \mathrm{M} \Omega \mathrm{cm}$ ) was obtained from an Elga Purelab flex water purification unit (Elga, Marlow, UK).

The pineapples were obtained from local markets. They were carefully washed with generous amounts of water and any strange material on the surface was removed. ${ }^{1,25}$ The samples were assessed using AOAC 2015.01 method, ${ }^{23}$ to ensure that the samples were free of $\mathrm{As}, \mathrm{Cd}, \mathrm{Hg}$ and $\mathrm{Pb}$.

Instrumentation

A quadrupole-based NexION 300D ICP-MS instrument with autosampler (PerkinElmer, Pennsylvania, USA) was used to measure $\mathrm{As}, \mathrm{Pb}, \mathrm{Cd}$ and $\mathrm{Hg}$. The plasma was generated using argon (99.990\%), a power of $1600 \mathrm{~W}$, gas flow rates of plasma $15 \mathrm{~L} \mathrm{~min}^{-1}$, auxiliary $1.2 \mathrm{~L} \mathrm{~min}^{-1}$, and nebulizer $0.52 \mathrm{~L} \mathrm{~min}^{-1}$. A cyclonic nebulizer, nickel sampler's and skimmer cones were used throughout the study. Torch position, ion lenses and gases output were optimized daily with the tuning solution $\left(1 \mu \mathrm{g} \mathrm{kg}^{-1}\right.$ of As, $\mathrm{Cd}, \mathrm{Ce}, \mathrm{Hg}$, and $\mathrm{Pb}$ in $2 \%(\mathrm{~m} / \mathrm{m}) \mathrm{HNO}_{3}$, density at $20{ }^{\circ} \mathrm{C}=1.0008 \mathrm{~kg} \mathrm{~m}^{-3}$ ), to maximize ion signals, and to minimize interference effects from polyatomic ions and doubly charged ions. A relative standard deviation (RSD) of $3 \%$ or lower was achieved in the signal of each probe element before any measurements on samples.

A Multiwave PRO microwave sample preparation system (Anton Paar, Graz, Austria), equipped with multipurpose rotor with 16 pressure vessels (PTFE-TFM ${ }^{\circledR}$ (modified-polytetrafluoroethylene) with average mass of $65 \mathrm{~g}$ ), supported by a vessel jacket made of ceramic was used. Vessel pressure and internal temperature were continuously controlled by wireless sensors in the first vial. An infrared (IR) sensor measured the temperature of all vessels continuously.

An XP504 balance (Mettler Toledo, Ohio, USA) was used for the gravimetric preparation of the solutions and the weighing of the pineapple samples. The accuracy of the balance was checked daily with check weights, finding errors less than $0.1 \mathrm{~g}$.

\section{Internal standard selection}

In this work, internal standards (IS) will be used for the correction of the instrumental drift in all measurements. 
Three possible IS, absent in the samples, were tested: Rh, $\mathrm{Tl}$, and $\mathrm{U}$ were assessed by comparing calibration linearity and repeatability. The concentration of each IS candidate was fixed at $1 \mu \mathrm{g} \mathrm{kg}^{-1}$. The criteria to select the best IS were content in the test sample (the lower, the better), linear correlation $\left(\mathrm{R}^{2}\right)$, percentage of relative standard deviation (RSD), and the similarity of the atomic mass respect to the analytes.

\section{Preliminary test}

The starting point for the sample digestion was taken from AOAC 2015.01 method. ${ }^{23}$ The lyophilized pineapple, around $300 \mathrm{mg}$, was weighed directly into a PTFE vessel, and it was added with $4 \mathrm{~mL} \mathrm{HNO}_{3}, 1 \mathrm{~mL} \mathrm{H}_{2} \mathrm{O}_{2}$, and $0.1 \mathrm{~g}$ of the IS solution. In the first step of the digestion procedure, the vessels were closed without compression for 10 to $20 \mathrm{~min}$. After that, the vessels were closed, threading the caps finger tight. The microwave was programmed according to the AOAC 2015.01 method. ${ }^{23}$

When the digestion process was finished, the vessels were allowed to cool to room temperature, vented and opened. The solution was transferred quantitatively to a polypropylene bottle and added with deionized water to complete close to $20 \mathrm{~g}$. This final solution was taken for the SAM experiments.

\section{Evaluation of the microwave assisted digestion method}

A PB experimental design was used to evaluate seven parameters: (i) mercury recovery improvement by addition of $0.5 \mathrm{~mL}$ of a $50 \mu \mathrm{g} \mathrm{kg}^{-1}$ solution of $\mathrm{Au}^{\text {III }}$ to the vessels; ${ }^{26}$ (ii) concentration of $\mathrm{HNO}_{3}$; (iii) highest temperature of the digestion $\left(\mathrm{T}_{\mathrm{Max}}\right)$; (iv) addition of an aliquot of concentrated $\mathrm{H}_{2} \mathrm{O}_{2}$; (v) pre-digestion stage (PD) in which initial heating was carried out at $145{ }^{\circ} \mathrm{C}$ and then decreased to $50{ }^{\circ} \mathrm{C}$, before starting the heating at the final temperature; (vi) time in the highest temperature $\left(\mathrm{t}_{\mathrm{TMax}}\right)$; and (vii) sample mass (m) ${ }^{6,9}$ The experimental design is shown in Table 1. All experiments were evaluated by triplicate.

The pineapple samples were fortified to obtain $10 \mu \mathrm{g}$ of $\mathrm{As}, \mathrm{Cd}, \mathrm{Hg}$, and $\mathrm{Pb}$ per $\mathrm{kg}$ of pineapple. This was done since these elements were not found in the studied pineapple samples. The percentage of RSD of the recovery was used as the quality function to evaluate the significance of the effects in the experimental design. Four reference values of RSD was used for the comparison purposes: (i) Horwitz RSD for the maximum level, $100 \mu \mathrm{g} \mathrm{kg}^{-1}$, in conditions of repeatability ${ }^{24}$ (5.7\%); (ii) Horwitz RSD for $10 \mu \mathrm{g} \mathrm{kg}^{-1}$ concentration of the analytes in the experimental design $(8 \%) ; ;^{27,28}$ (iii) half the average value of the recovery percentage given by the $\mathrm{AOAC}^{23}$ for a concentration of $10 \mu \mathrm{g} \mathrm{kg}^{-1}$ (12.5\%); and (iv) expanded uncertainty of a similar certified reference material $(5 \%){ }^{29}$

All the statistical studies were made using software $\mathrm{R}$ 3.4. $4^{30}$ and packages FrF2 and pid.

\section{Standard addition method}

The amount of standard to be added was studied, making additions of 10,30, and $50 \%$ of the approximate concentration in the sample to be tested. Based on our previous experiments, ${ }^{31,32}$ the concentration of the highest standard to be added should be 1 to 2 times the concentration in the sample solution. This was done considering the linearity of the ICP-MS instrument.

The concentration of the sample was calculated through equation 1:

$$
\frac{\mathrm{W}_{\mathrm{IS}}}{\mathrm{W}_{\mathrm{Sa}}} \times \frac{\mathrm{R}_{\mathrm{a}}}{\mathrm{R}_{\mathrm{IS}}}=\mathrm{S}\left(\frac{\mathrm{W}_{\mathrm{P}}}{\mathrm{W}_{\mathrm{Sa}}} \times \mathrm{C}_{\mathrm{P}}\right)+\mathrm{C}_{\mathrm{S}}
$$

where $\mathrm{W}_{\mathrm{IS}}$ : mass of IS $(\mathrm{g}) ; \mathrm{W}_{\mathrm{Sa}}$ : mass of sample $(\mathrm{g}) ; \mathrm{R}_{\mathrm{a}}$ : analyte instrumental response; $\mathrm{R}_{\mathrm{IS}}$ : internal standard

Table 1. Plackett-Burman design to evaluate the effect of the digestion parameters over the relative standard deviation of the content of As, Cd, $\mathrm{Hg}$, and $\mathrm{Pb}$ in pineapple

\begin{tabular}{|c|c|c|c|c|c|c|c|}
\hline Experiment & $\mathrm{Au}^{\mathrm{III}}$ & $\mathrm{HNO}_{3} /\left(\mathrm{mol} \mathrm{L}^{-1}\right)$ & $\mathrm{T}_{\text {Max }} /{ }^{\circ} \mathrm{C}$ & $\mathrm{H}_{2} \mathrm{O}_{2} / \mathrm{mL}$ & PD & $\mathrm{t}_{\mathrm{TMax}} / \min$ & $\mathrm{m} / \mathrm{g}$ \\
\hline 1 & no & 14 & 190 & 1 & yes & 15 & 0.3 \\
\hline 2 & no & 7 & 180 & 1 & yes & 10 & 0.3 \\
\hline 3 & yes & 7 & 180 & 2 & yes & 15 & 0.3 \\
\hline 4 & no & 14 & 180 & 2 & yes & 10 & 0.5 \\
\hline 5 & yes & 14 & 190 & 2 & no & 10 & 0.3 \\
\hline 6 & no & 7 & 190 & 2 & no & 15 & 0.5 \\
\hline 7 & yes & 7 & 190 & 1 & no & 10 & 0.5 \\
\hline 8 & yes & 14 & 180 & 1 & no & 15 & 0.5 \\
\hline
\end{tabular}

$\mathrm{T}_{\mathrm{Max}}$ : highest temperature of the digestion; $\mathrm{PD}$ : pre-digestion stage; $\mathrm{t}_{\mathrm{TMax}}$ : time in the highest temperature; m: sample mass. 
instrumental response; $\mathrm{S}$ : slope; $\mathrm{W}_{\mathrm{P}}$ : mass of standard $(\mathrm{g}) ; \mathrm{C}_{\mathrm{P}}$ : standard concentration $\left(\mu \mathrm{g} \mathrm{kg}^{-1}\right)$; $\mathrm{C}_{\mathrm{S}}$ : sample concentration $\left(\mu \mathrm{g} \mathrm{kg}^{-1}\right)$.

\section{Method validation}

The parameters used to validate our protocol were: linearity, precision, recovery, limit of detection, and selectivity. The method was validated at the intra-laboratory level using a simple blind method. ${ }^{4,19,21,33}$

\section{Linearity}

The calibration solutions were prepared by appropriate dilution of the stock solution in a blank matrix extract at concentrations between 0.010 and $1.2 \mu \mathrm{g} \mathrm{kg}^{-1}$.

\section{Accuracy}

Precision (under repeatability conditions) and trueness as recovery percentage $(\mathrm{R})$ were assessed using spiked samples at three concentration levels, between 50 to $200 \mu \mathrm{g} \mathrm{kg}^{-1}$. The RSD and recovery values were calculated on a set of replicated samples, $n=7$.

Limits of detection (LOD)

LOD was calculated according to IUPAC ${ }^{34}$ recommendation with ten replicas of the blank.

\section{Selectivity}

The presence of potential interferences from the analyzed samples was made using control pineapple samples without $\mathrm{As}, \mathrm{Cd}, \mathrm{Hg}$, and $\mathrm{Pb}$, and with the same samples spiked with $0.350 \mu \mathrm{g} \mathrm{kg}^{-1}$. The criterion to evaluate the selectivity was the signal-to-noise ratio at the $m / z$ of each element. In this way, it is possible to identify the presence of spectral interferences such as ${ }^{40} \mathrm{Ar}{ }^{35} \mathrm{Cl}$, which can generate overestimations in the quantification of the analytes. When the signal-to-noise ratio was bigger than six, we assumed that no interferences were present. ${ }^{19,28,34}$

\section{In-house reference material preparation}

The in-house reference materials (iHRM) were prepared according to guide ISO 80:2014. ${ }^{18}$ Three pineapples without crown were used; its weigh was about $4 \mathrm{~kg}$. The shell was removed, and the pulp was processed in a food kitchen chopper for $5 \mathrm{~min}$. The crushed pulp $(677.4 \mathrm{~g}$ ) was fortified with $254 \mathrm{~mL}$ of a multi-elemental solution of $\mathrm{As}, \mathrm{Cd}, \mathrm{Hg}$, and $\mathrm{Pb}$ to obtain an approximate final concentration of $100 \mu \mathrm{g} \mathrm{kg}^{-1}$ in each analyte (regulation levels given by the FAO) ${ }^{25}$ The fortified pineapple was homogenized in a food kitchen chopper for $10 \mathrm{~min}$ and divided into three parts: $300 \mathrm{~g}$ were lyophilized (iHRM-1), $300 \mathrm{~g}$ were dried in an oven at $50{ }^{\circ} \mathrm{C}$ (iHRM-2), and the rest (about $77 \mathrm{~g}$ ) was stored at $-20^{\circ} \mathrm{C}$ (iHRM-3).

The two dried products were sieved to obtain particles lower than $500 \mu \mathrm{m}$ in size. Then, $20 \mathrm{~g}$ of each pineapple dust was packed in amber glass bottles of $125 \mathrm{~mL}$, iHRM-1 and iHRM-2. Enough space was left in the bottles to allow homogenization before use.

The characterization of the iHRMs was made by the values assignment to each analyte, the homogeneity and the stability assessments. The values assigned to each candidate were tested using the method, previously validated, and by making the analysis three times on each material. The assessing of homogeneity was made using $0.5 \mathrm{~g}$ of each material. The procedure was repeated ten times for the candidates: iHRM-1, iHRM-2, and iHRM-3. The samples were measured 15 times in the ICP-MS, and the concentration results presented in dry mass. The uncertainty associated with the homogeneity of the in-house materials was estimated according to ISO 35:201722 for $\mathrm{As}, \mathrm{Cd}, \mathrm{Hg}$, and $\mathrm{Pb}^{20,35}$ Considering that the analyzed elements were not found in the studied pineapple samples, it was decided to evaluate, also, $\mathrm{Cu}$ and $\mathrm{Fe}$, which naturally occur in pineapples. These elements were chosen because the National Metrology Institute of Colombia has a validated methodology to measure them in several food matrices (see Supplementary Information (SI) section). The dry mass correction factor was calculated using 1 - (moisture $(\%) / 100$ ). The moisture of the iHRMs was determined in three separate portions, each one close to $5 \mathrm{~g}$. The samples were dried in an oven for two hours.

The stability of the candidates was evaluated gravimetrically through an isochronous design..$^{22}$ Each material $(2 \mathrm{~g})$ was packed in $10 \mathrm{~g}$ amber bottles and sealed in a vacuum bag. The reference temperature was $-30^{\circ} \mathrm{C}$, and the samples were subjected to a climatization chamber at $45{ }^{\circ} \mathrm{C}$ and humidity of $40 \%$. The stability study lasted 90 days.

\section{Results and Discussion}

\section{Preliminary test}

The results from the preliminary test, using AOAC 2015.01, ${ }^{23}$ showed that, $\mathrm{As}, \mathrm{Cd}, \mathrm{Hg}$, and $\mathrm{Pb}$ were not present in the studied pineapple samples. For this reason, the samples used in this work were fortified.

\section{Evaluation of the IS}

Two criteria were employed to establish the most suitable IS to quantify $\mathrm{As}, \mathrm{Cd}, \mathrm{Hg}$, and $\mathrm{Pb}$, simultaneously, 
Table 2. Global significance percentage (GSP) of the variables in the digestion procedure evaluated according to equation S1 (SI section) and the effect of those variables over repeatability

\begin{tabular}{|c|c|c|c|c|}
\hline Parameter & AOAC $2015.01^{23}$ & GSP / $\%$ & $\begin{array}{c}\text { Repeatability improvement } \\
\text { due to change }\end{array}$ & This work \\
\hline $\mathrm{m} / \mathrm{g}$ & 0.3 & 11 & no & no change \\
\hline PD & yes & 13 & no & no change \\
\hline $\mathrm{t}_{\mathrm{TMax}} / \min$ & 15 & 13 & no & no change \\
\hline $\mathrm{Au}^{\mathrm{III}}$ & yes & 15 & yes & without $\mathrm{Au}$ \\
\hline $\mathrm{HNO}_{3} /\left(\mathrm{mol} \mathrm{L}^{-1}\right)$ & 14 & 15 & yes & 7 \\
\hline $\mathrm{H}_{2} \mathrm{O}_{2} / \mathrm{mL}$ & 1 & 16 & no & no change \\
\hline $\mathrm{T}_{\mathrm{Max}} /{ }^{\circ} \mathrm{C}$ & 190 & 18 & yes & 180 \\
\hline
\end{tabular}

GSP: global significance percentage; m: sample mass; PD: pre-digestion stage; $\mathrm{t}_{\mathrm{TMax}}$ : time in the highest temperature; $\mathrm{T}_{\mathrm{Max}}$ : highest temperature of the digestion.

in pineapple: (i) linearity, and (ii) the percentage of RSD. The best linear calibration functions were obtained for $\mathrm{Rh}\left(\mathrm{R}^{2}=0.998\right.$, residuals $\left.<2 \%\right)$ compared with $\mathrm{Tl}\left(\mathrm{R}^{2}=\right.$ 0.992 , residuals $<3 \%)$ and $U\left(R^{2}=0.948\right.$, residuals $\left.>3 \%\right)$. On the other hand, the RSD (instrumental) was only $2.0 \%$ when $\mathrm{Rh}$ was used, meanwhile for $\mathrm{Tl}$ was $2.8 \%$, and $5 \%$ for uranium. Thus, the IS selected for the development and method validation was $\mathrm{Rh}$.

Plackett-Burman (PB) design to evaluate the microwaveassisted digestion method

The significance of the PB experimental design variables was evaluated through the global significance percentage (GSP), which is explained in the SI section. The variables with GSP greater than or equal to $14 \%$ were established as significant. However, not only the GSP value was considered to change a parameter, the improvement of the repeatability, "yes" or "no" in Table 2, was also considered to determine if the value of a variable under study must be changed or not. In this way, the amount of $\mathrm{H}_{2} \mathrm{O}_{2}$ in $\mathrm{mL}$, although critical, was not changed because the proposed change, an increase in the amount of $\mathrm{H}_{2} \mathrm{O}_{2}$, produce the decrease of the repeatability. Then it is better to maintain unchanged the low amount of $\mathrm{H}_{2} \mathrm{O}_{2}$. Table 2 resumes these results and shows the digestion conditions that were chosen for the rest of the work; column 2, where no changes were made (AOAC 2015.01) ${ }^{23}$ and column 5, where changes were made.

The improved digestion conditions are compared to the AOAC method 2015.0123 in Table 3, which shows the RSD obtained for the two methods. These results were obtained for spiked samples to $100 \mu \mathrm{g} \mathrm{kg}^{-1}$. Table 3 shows that the improved digestion process reduces the random errors generated during the sample mineralization since it increases the precision in repeatability conditions. ${ }^{6,9}$
Finally, it is important to mention that after the digestion, all the pineapple samples were transparent solutions, with no visible solid residue.

Table 3. Precision obtained (RSD) for the digestion methods: AOAC $2015.01^{23}$ and the one developed in this work

\begin{tabular}{lcc}
\hline \multirow{2}{*}{ Element } & \multicolumn{2}{c}{ RSD / \% } \\
\cline { 2 - 3 } & AOAC 2015.01 & This work \\
\hline $\mathrm{As}$ & 9.8 & 4.4 \\
$\mathrm{Cd}$ & 5.3 & 1.4 \\
$\mathrm{Hg}$ & 6.2 & 5.6 \\
$\mathrm{~Pb}$ & 7.5 & 3.8 \\
\hline
\end{tabular}

RSD: residual standard deviation.

Method validation

\section{Linearity and matrix effects}

The linearity of the analytical curves was evaluated in $1 \% \mathrm{HNO}_{3}$ in a twenty-point plot with three replicates and by the calculation of the linear regression squared correlation coefficient $\left(R^{2}\right)$, which always was $>0.9900$. The lowest concentration level in the calibration curve was established as the concentration with a signal-to-noise ratio, at least, greater than 10 . The model was validated using the residual analysis, which should be $<10 \%$ and regression analysis of variance (ANOVA two-way). ${ }^{19,21}$ Good agreement between experimental and expected contents for the four elements was observed, with residuals values always lower than $8 \%$. Table 4 shows the final linear intervals selected and the maximum residual obtained for each element.

Considering a real sample, ${ }^{16}$ pineapple, the matrix effect can be studied by comparison of the slopes of the calibration curves in a matrix (pineapple extracts) and in pure $1 \% \mathrm{HNO}_{3}$. A signal enhancement, a slope ratio $>1$, or a suppression effect, a slope ratio $<1$, it is acceptable if 
Table 4. Validation parameters: linearity and matrix effect

\begin{tabular}{lccc}
\hline Element & $\begin{array}{c}\text { Linear interval }^{\mathrm{a}} / \\
\left(\mu \mathrm{g} \mathrm{kg}^{-1}\right)\end{array}$ & $\begin{array}{c}\text { Maximum } \\
\text { residual } \\
\text { obtained / \% }\end{array}$ & $\begin{array}{c}\text { Slope ratio: } \\
\text { matrix/HNO }\end{array}$ \\
\hline $\mathrm{As}$ & $0.01-1.0$ & 2.80 & 1.6 \\
$\mathrm{Cd}$ & $0.01-1.0$ & 2.20 & 1.6 \\
$\mathrm{~Pb}$ & $0.07-0.8$ & 3.50 & 3.0 \\
$\mathrm{Hg}$ & $0.1-0.9$ & 7.10 & 3.1 \\
\hline
\end{tabular}

a The linear interval is presented in $\mu \mathrm{g}$ of the element per kilogram of digestion extract.

this ratio is between 1.2 to $0.8 .^{16,17}$ The results in Table 4 (last column) show slope ratios higher than this interval. Then, an enhancement matrix effect is evident in the four elements and particularly for $\mathrm{Pb}$ and $\mathrm{Hg}$.

\section{Selectivity}

No interferences were observed at the $\mathrm{m} / \mathrm{z}$ ratios and conditions used in this research. The developed digestion method is a suitable protocol for the sample preparation in order to make the quantification of $\mathrm{As}, \mathrm{Cd}, \mathrm{Hg}$, and $\mathrm{Pb}$ by ICP-MS, in pineapple. However, the most marked effects are the acidity of the sample and the memory effect, which is generated mainly in the determination of $\mathrm{Hg} \cdot{ }^{13} \mathrm{~A}$ rinse with nitric acid (5\%) and 2-mercaptoethanol $(0.5 \%)$, between sample measurements, was necessary to avoid the latter effect. ${ }^{31}$ Additionally, it is important to notice that no chloride-based acids were added as digestion reagents. In this way, the interferences of ${ }^{40} \mathrm{Ar}^{35} \mathrm{Cl}$ were negligible on ${ }^{75} \mathrm{As}$, and no corrections were necessary for the calculations. This fact was verified by comparing the results obtained in the standard mode of the ICP-MS, with those of the kinetic energy discrimination (KED) mode. The effect of ${ }^{40} \mathrm{Ar}^{35} \mathrm{Cl}$ over the signal-to-noise ratio was found insignificant. ${ }^{15,32}$

\section{Trueness and precision}

According to the previous experiments in the NMI of Colombia, ${ }^{31,32}$ in any case, it is required to find the best concentration interval to construct the standard addition curve (analyte and sample), before the evaluation of trueness and precision. In this work, those intervals were found in a study of the increase of the standard calibration concentration over the sample. Three percentages of the increase were studied: 10,30 , and $50 \%$ of the digested pineapple concentration spiked with $100 \mu \mathrm{g} \mathrm{kg}{ }^{-1}$ of each analyte. Table 5 summarizes the obtained recovery percentages for this test.

Table 5. Recovery percentages calculated at $\mathrm{As}, \mathrm{Cd}, \mathrm{Hg}$ and $\mathrm{Pb}$ concentrations of $100 \mu \mathrm{g} \mathrm{kg}^{-1}$ in pineapple and different percentages of increase in the concentration of the analytes

\begin{tabular}{lccc}
\hline \multirow{2}{*}{ Element } & \multicolumn{3}{c}{ Recovery / \% } \\
\cline { 2 - 4 } & $10 \%$ increase & $30 \%$ increase & $50 \%$ increase \\
\hline $\mathrm{As}$ & 92.55 & 101.04 & 99.8 \\
$\mathrm{Cd}$ & 90.47 & 95.24 & 99.8 \\
$\mathrm{Hg}$ & 94.34 & 105.23 & 98.4 \\
$\mathrm{~Pb}$ & 74.56 & 100.87 & 99.8 \\
\hline
\end{tabular}

The increase is over extract concentration.

Table 5 shows that the increases of 30 and $50 \%$ of the concentration present the best recovery percentages. On the contrary, with increases of $10 \%$, it was not possible to achieve good recoveries for $\mathrm{Cd}$ and $\mathrm{Pb}$. ANOVA test $(p>0.05)$ indicates that no significant differences exist between the recoveries obtained for 30 and $50 \%$. However, statistical differences between RSDs for 30\% (RSD $=5 \%$ ) and $50 \%(\mathrm{RSD}=1 \%)$ were found (Levene's test $p<0.05)$. This means that the best increase in concentration for addition standard calibration is $50 \%$ of the digested pineapple concentration spiked with $100 \mu \mathrm{g} \mathrm{kg}^{-1}$ of each analyte.

After the adjustment of the previous parameters, the trueness of the analytical procedure was estimated by the evaluation of the spiked pineapple samples. Recoveries and relative standard deviations obtained for seven replicate samples of pineapple, spiked at three different concentration levels, are reported in Table 6. The recoveries

Table 6. Relative standard deviations (RSD), recovery, and limits of detection (LOD) of $\mathrm{As}, \mathrm{Cd}, \mathrm{Hg}$ and $\mathrm{Pb}$ determination in pineapple

\begin{tabular}{|c|c|c|c|c|c|}
\hline & $\begin{array}{l}\text { Concentration in the } \\
\text { sample / }\left(\mu \mathrm{g} \mathrm{kg}^{-1}\right)\end{array}$ & As & $\mathrm{Cd}$ & $\mathrm{Hg}$ & $\mathrm{Pb}$ \\
\hline \multirow{3}{*}{$\mathrm{RSD} / \%$} & 50 & 4.3 & 1.4 & 9.8 & 3.8 \\
\hline & 100 & 4.4 & 3.6 & 5.7 & 7.8 \\
\hline & 200 & 3.1 & 1.5 & 9.5 & 2.2 \\
\hline \multirow{3}{*}{ Recovery / \% } & 50 & 99.8 & 99.8 & 97.0 & 99.8 \\
\hline & 100 & 100.1 & 100.3 & 101.3 & 101.5 \\
\hline & 200 & 101.6 & 101.8 & 112.2 & 101.4 \\
\hline $\mathrm{LOD} /\left(\mu \mathrm{g} \mathrm{kg}^{-1}\right.$ in sample $)$ & & 14.2 & 1.5 & 21.9 & 5.4 \\
\hline
\end{tabular}


were between 97 and 112\%, which is a satisfactory performance according to the AOAC method. ${ }^{23}$ The trueness of the method was verified through the Student's $t$-test $(p<0.05)$, the details of these calculations are in the SI section. According to the AOAC method, the recovery obtained during the validation of the method must be $100 \pm 25 \%$, but for this work, the criterion was adjusted to a smaller interval: $100 \pm 15 \%$ (85-115\%). Under this criterion, all the analyzed elements in pineapple showed a particularly good recovery. ${ }^{25}$

The results obtained from the trueness experiments were used to estimate the precision of the method. The precision of the method was evaluated in repeatability conditions (variation of the results obtained in the same series) and was expressed as RSD. The RSD values, presented in Table 6, were less than $10 \%$ for all the concentration levels and elements tested. According to AOAC method, ${ }^{23}$ the maximum RSD obtained during the validation of the method should be less than $15 \%$, then it is possible to conclude that the method developed is precise under repeatability conditions.

\section{Limit of detection}

LODs were calculated as three times the standard deviation of ten blank pineapple samples, multiplied by the dilution factor according to IUPAC recommendation. ${ }^{32}$ Table 6 shows these results. The detection limits were verified by determining the signal-to-noise ratio $(\mathrm{S} / \mathrm{N})$ of samples in concentrations at the LOD. We tested the LODs and the $\mathrm{S} / \mathrm{N}$ calculated were than greater than 3 . The LOD for $\mathrm{Hg}$ was the highest due to problems related to low response of this element and the memory effect. ${ }^{13}$

It is important to remember that, in the quantification of toxic elements in fruits, several analytical methods require a pre-concentration step before the detection measurements. The typical low LOD of the ICP-MS, combined with the method developed in this work, makes us avoid that pre-concentration step because our LODs and limit of quantification (LOQ) values are below the $\mathrm{FAO}^{25}$ regulations levels for $\mathrm{As}, \mathrm{Cd}, \mathrm{Hg}$, and $\mathrm{Pb}$ in fruits.

\section{Characterization of the pineapple in-house reference materials (iHRMs)}

\section{Value assignment}

The values assigned to the pineapple iHRMs were performed using the developed method for the quantification of $\mathrm{As}, \mathrm{Cd}, \mathrm{Hg}$, and $\mathrm{Pb}$. The data were corrected for the humidity of the material. The pineapple in-house reference materials iHRM-1 (lyophilized) and iHRM-2 (dried in oven) were made to obtain a time stable material. The third,
iHRM-3 (not lyophilized or dried in oven), was used as a fast testing reference to estimate the expected values in the iHRMs and to calculate the efficiency of the lyophilization and the drying in oven processes.

The expected concentration for iHRM-3 is close to $100 \mu \mathrm{g} \mathrm{kg}^{-1}$ in wet mass and $1200 \mu \mathrm{g} \mathrm{kg}^{-1}$ in dry mass for each analyte; however, it was found that the average concentration for $\mathrm{As}, \mathrm{Pb}$, and $\mathrm{Cd}$ was about $17 \%$ lower than the expected value, and $10 \%$ higher for $\mathrm{Hg}$. Table 7 shows these results. It is not easy to find an explanation for this fact, and then no hypothesis will be done because the purpose of these experiments is to obtain a known concentration, homogeneous, and stable iHRM.

Table 7. Concentration of $\mathrm{As}, \mathrm{Cd}, \mathrm{Hg}$, and $\mathrm{Pb}$ in the in-house reference materials iHRM-1, iHRM-2, and iHRM-3. The concentration is given in dry mass

\begin{tabular}{lccc}
\hline \multirow{2}{*}{ Element } & \multicolumn{3}{c}{ Concentration $/\left(\mu \mathrm{g} \mathrm{kg}^{-1}\right)$} \\
\cline { 2 - 4 } & iHRM-1 & iHRM-2 & iHRM-3 \\
\hline $\mathrm{As}$ & 794.1 & 987.2 & 1212.1 \\
$\mathrm{Cd}$ & 647.4 & 979.4 & 1002.3 \\
$\mathrm{Hg}$ & 887.3 & 1122.7 & 1240.9 \\
$\mathrm{~Pb}$ & 763.8 & 981.9 & 1149.0 \\
\hline
\end{tabular}

iHRM: in-house reference material.

The characterization results for the iHRM-1 and iHRM-2 are presented in Table 7. It is evident, from Table 7 that the iHRM-2 has higher concentration values than the iHRM-1. The difference is due to the losses of the volatile compounds of the pineapple, resulting from the heating process in the oven at $50{ }^{\circ} \mathrm{C}$ (iHRM-2). This fact increases the mass fraction of the analytes in iHRM-2, while the lyophilization process (iHRM-1) avoids the loss of those volatile compounds, ${ }^{18,36}$ given as a result, lower concentrations for the iHRM-1.

\section{Homogeneity test for the pineapple iHRMs}

The homogeneity test for the iHRMs were made using the ANOVA $F$-tests. The results, for the homogeneity of the three materials, were not significant at the $95 \%$ confidence level. This indicates that the pineapple materials are homogeneous. Then, the homogeneity uncertainty of the three pineapple iHRMs was calculated based on the $\mathrm{As}, \mathrm{Cd}, \mathrm{Hg}$, and $\mathrm{Pb}$ instrumental responses, and it was evaluated only within the bottle. Furthermore, the homogeneity uncertainty was compared with the signals of $\mathrm{Cu}$ and $\mathrm{Fe}$ because these elements are naturally present in pineapple. The analysis of these natural elements $(\mathrm{Cu}$ and $\mathrm{Fe}$ ) was performed with a previously validated method (see SI section). The results of the latter analysis showed 
an RSD of $2.7 \%$ for $\mathrm{Cu}$, and $1.1 \%$ for $\mathrm{Fe}$. The biases were $2.0 \%$ for $\mathrm{Cu}$, and $1.8 \%$ for $\mathrm{Fe}$.

Figure 1 shows the homogeneity uncertainties of the iHRM-1, iHRM-2, and iHRM-3 (calculated using the ANOVA). These results demonstrate, based on the results for the signals of $\mathrm{Cu}$ and $\mathrm{Fe}$, that the uncertainty due to natural heterogeneity was, approximately, between 0.7 and $1.8 \%$. Also, Figure 1 shows that the spiked elements $\mathrm{Cd}$ and As have very similar heterogeneity. These facts indicate that the fortification process was efficient. On the other hand, the three iHRMs have similar uncertainties for the natural elements. This means that the drying and sieving treatments were satisfactory.

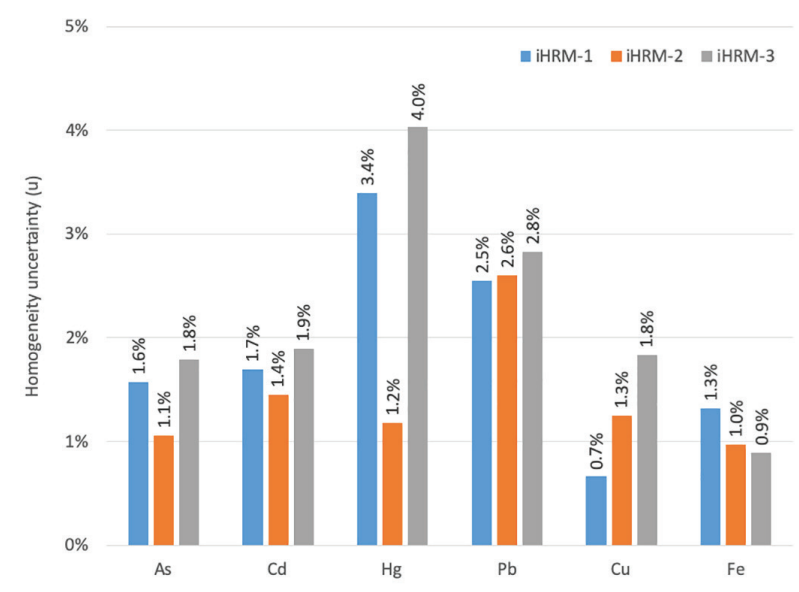

Figure 1. Percentage of homogeneity uncertainty for the pineapple inhouse reference materials: iHRM-1 lyophilized, iHRM-2 dried in oven and iHRM-3 not dried.

Figure 1 also shows that the homogeneity uncertainty is similar in iHRM-1 and iHRM-2, which indicates that either of the two drying procedures proposed can be applied to obtain this kind of in-house reference materials. Additionally, and in order to establish the qualities of our in-house reference materials, a comparison was made with a similar reference material used in CCQM-K108 ${ }^{37}$ and CCQM-K145 ${ }^{38}$ comparisons, which have a reported relative uncertainty for homogeneity between 0.81 and $1.6 \% .{ }^{37,39}$ These values are certainly lower than our
iHRMs homogeneity uncertainty, but not so much and not always, see Figure 1. Then, our developed iHRMs are suitable for quality control in a routine or regulatory laboratory.

Considering the results shown in Figure 1 and Table 7, and from the point of view of the developed method for the quantification of $\mathrm{As}, \mathrm{Cd}, \mathrm{Hg}$, and $\mathrm{Pb}$ in pineapple, it is evident that the developed method is good enough for the determination of the four elements in pineapple.

\section{Stability of the pineapple iHRMs}

The production of the iHRMs was made taking care of the following points: $(i)$ the iHRMs were prepared according to guide ISO $80: 2014 ; i^{18}$ (ii) the water was removed to prevent the enzymatic, chemical and microbiological activities; and (iii) the iHRMs were packed in amber glass and vacuum packed (aluminum foil) to reduce the influence of light. Under these circumstances, a short-term isochronous stability ${ }^{22}$ study was carried out at $45{ }^{\circ} \mathrm{C}$ and humidity of $40 \%$ (iHRM- 1 and HRM-2). The results of this study allow us to say that the iHRMs are stable for 90 days (see SI section). Also, these results show a higher slope for iHRM-2 with respect to the iHRM-1. This indicates that the iHRM-2 is more unstable. This situation is due to the fact that the lyophilized materials (iHRM-1) can be rehydrated rapidly because this drying process conserves the structural properties of the material, while drying in oven affects the chemical composition of the matrix. ${ }^{36}$

The conclusion of the stability experiment, and according to ISO guide $35,{ }^{22}$ is that the uncertainties of stability $\left(\mathrm{u}_{\mathrm{stab}}\right.$ ) estimated for 90 days for the iHRM-1 and iHRM-2 is less than $1 \%$. It is important to mention that these uncertainties were less than the accepted interval established on ISO 80:2014 ${ }^{18}$ (2.5 to $7.3 \%$ ).

\section{Combined uncertainties of the pineapple iHRMs}

Table 8 shows the contribution of the homogeneity $\left(\mathrm{u}_{\text {hom }}\right)$, stability $\left(\mathrm{u}_{\text {stab }}\right)$, and measurement $\left(\mathrm{u}_{\text {meas }}\right)$ uncertainties to the total uncertainties of the iHRMs.

Table 8. Relative uncertainty sources for in-house reference materials iHRM-1 and iHRM-2

\begin{tabular}{|c|c|c|c|c|c|c|c|c|}
\hline \multirow{2}{*}{ Element } & \multicolumn{4}{|c|}{ Relative uncertainty in iHRM-1/\% } & \multicolumn{4}{|c|}{ Relative uncertainty in iHRM-2 / \% } \\
\hline & $\mathrm{u}_{\text {stab }}$ & $\mathrm{u}_{\text {hom }}$ & $\mathrm{u}_{\text {meas }}$ & $\mathrm{u}_{\text {mat }}$ & $\mathrm{u}_{\text {stab }}$ & $\mathrm{u}_{\mathrm{hom}}$ & $\mathrm{u}_{\text {meas }}$ & $\mathrm{u}_{\text {mat }}$ \\
\hline As & 0.66 & 1.60 & 1.53 & 2.31 & 0.61 & 1.10 & 1.18 & 1.73 \\
\hline $\mathrm{Cd}$ & 0.66 & 1.70 & 1.66 & 2.47 & 0.61 & 1.40 & 1.50 & 2.14 \\
\hline $\mathrm{Hg}$ & 0.66 & 4.40 & 1.77 & 4.79 & 0.61 & 1.20 & 1.53 & 2.04 \\
\hline $\mathrm{Pb}$ & 0.66 & 2.50 & 2.41 & 3.54 & 0.61 & 2.60 & 2.54 & 3.68 \\
\hline
\end{tabular}

$\mathrm{u}_{\text {stab }}$ : uncertainty of stability; $\mathrm{u}_{\text {hom }}$ : uncertainty of homogeneity; $\mathrm{u}_{\text {meas }}$ : uncertainty of measurement; $\mathrm{u}_{\text {mat }}$ : uncertainty of material. This table is presented in $\mu \mathrm{g} \mathrm{kg}{ }^{-1}$ (typical uncertainty) units in Table S7 (SI section). 


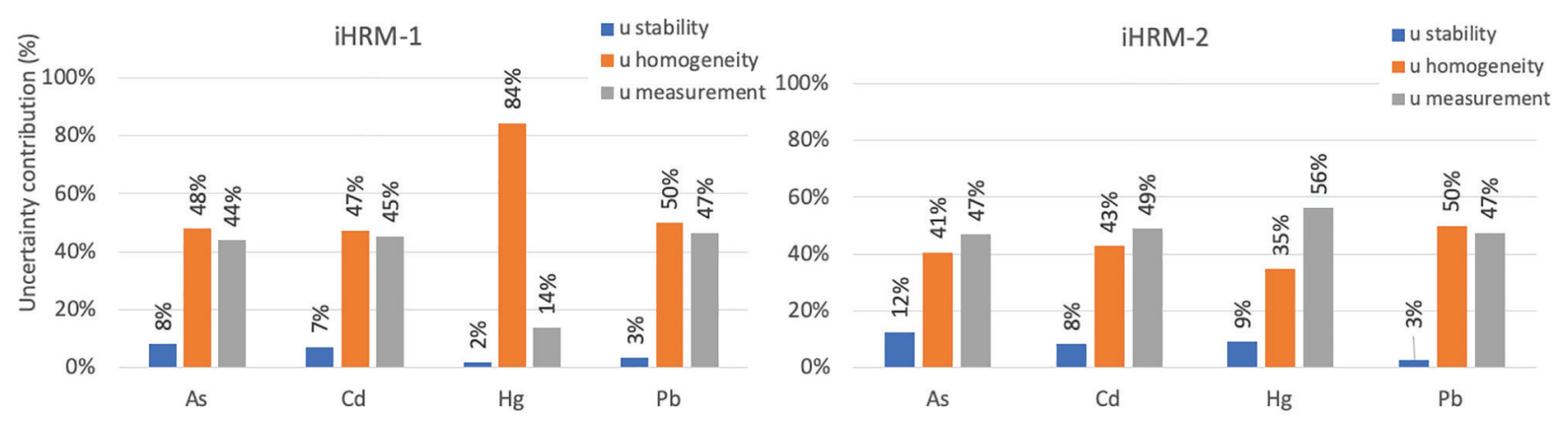

Figure 2. Uncertainty contribution of stability, homogeneity and measurement to the total uncertainty of the in-house reference materials iHRM-1 and iHRM-2.

The contribution of each source to the relative combined uncertainties is shown in Figure 2. Table 8 and Figure 2 show that the contribution from the measurement and the homogeneity were the major sources of uncertainty, and the instability of the in-house reference materials did not contribute very much to the material uncertainty.

According to the previous facts, the developed pineapple in-house reference materials, iHRM-1 and iHRM-2, have been demonstrated to be good candidates as internal quality control in the determination of $\mathrm{As}, \mathrm{Cd}$, $\mathrm{Hg}$ and $\mathrm{Pb}$ in Colombian pineapple. ${ }^{18}$

Finally, and considering the next two facts: (i) the prepared in-house reference material have an uncertainty lower than $5 \%$ and (ii) the $\mathrm{u}_{\text {target }}=12 \%$ for the concentration level used (according to Hortwitz equation), it can be concluded that the material is adequate for the purpose (quality control) used in this research.

\section{Conclusions}

A quantification method for $\mathrm{As}, \mathrm{Cd}, \mathrm{Hg}$, and $\mathrm{Pb}$ in pineapple, using ICP-MS, was developed and validated. The obtained results are in accordance and, in many cases, have superior performance with respect to the requirements of the AOAC 2015.01 method. Our PlackettBurman design results allowed us to reduce the random errors of the microwave digestion procedure of the AOAC method.

A gravimetric standard addition method (SAM) was used to minimize the matrix effect. The elimination of memory effect, presented only by $\mathrm{Hg}$, was achieved by a rinse with nitric acid (5\%) and 2-mercaptoethanol $(0.5 \%)$ between sample measurements. At the improved conditions, and under the validation conditions (including the low enough limits of detection), the developed method guarantees a confident determination of the concentrations of $\mathrm{As}, \mathrm{Cd}, \mathrm{Hg}$, and $\mathrm{Pb}$ in Colombian pineapple.

The validated method for the quantification of As, $\mathrm{Cd}, \mathrm{Hg}$, and $\mathrm{Pb}$ was applied to the value assignment and the assessment of the homogeneity and stability of the pineapple iHRMs. The relative uncertainty due to the material homogeneity was lower than $4 \%$, lower than $1 \%$ for the stability uncertainty, and the measurement uncertainty was lower than 5\%. The measurement uncertainty was the most significant source of uncertainty with a contribution close to $56 \%$ of the total uncertainty. Considering these facts, the iHRMs developed in this work are suitable to be used as quality control in the analytical methods to quantify $\mathrm{As}, \mathrm{Cd}, \mathrm{Hg}$, and $\mathrm{Pb}$ in Colombian pineapple.

\section{Supplementary Information}

Supplementary data are available free of charge at http://jbcs.sbq.org.br as PDF file.

\section{Acknowledgments}

The authors are grateful to the Instituto Nacional de Metrología (INM) of Colombia and the Universidad Nacional de Colombia through the project "Determinación de elementos tóxicos en productos agrícolas: $\mathrm{Pb}$ en piña y Hg en tilapia y trucha" (HERMES 35551).

\section{References}

1. Medina, J. C.; García, H. S.; PINEAPPLE: Post-harvest Operations, $1^{\text {st }}$ ed.; Mejía, D., ed.; Food and Agriculture Organization of the United Nations: Veracruz, 2005.

2. Global Agricultural Trade and Developing Countries; Aksoy, M. A.; Beghin, J. C., eds.; $1^{\text {st }}$ ed.; The World Bank: Washington, DC, 2004.

3. Chevallier, E.; Chekri, R.; Zinck, J.; Guérin, T.; Noël, L.; J. Food Compos. Anal. 2015, 41, 35.

4. The Fitness for Purpose of Analytical Methods - A Laboratory Guide to Method Validation and Related Topics, $2^{\text {nd }}$ ed.; Magnusson B.; Örnemark, U., eds.; Eurachem, 2014. Available at https://www.eurachem.org/index.php/publications/guides/ mv, accessed in January 2020. 
5. Elbagermi, M. A.; Edwards, H. G. M.; Alajtal, A. I.; ISRN Anal. Chem. 2012, 2012, DOI 10.5402/2012/827645.

6. Enamorado-Báez, S. M.; Abril, J. M.; Gómez-Guzmán, J. M.; ISRN Anal. Chem. 2013, 2013, DOI 10.1155/2013/851713.

7. Entwistle, J. A.; Amaibi, P. M.; Dean, J. R.; Deary, M. E.; Medock, D.; Morton, J.; Rodushkin, I.; Bramwell, L.; Environ. Int. 2019, 122, 130.

8. Bakkali, K.; Martos, N. R.; Souhail, B.; Ballesteros, E.; Anal. Lett. 2012, 45, 907.

9. Bressy, F. C.; Brito, G. B.; Barbosa, I. S.; Teixeira, L. S. G.; Korn, M. G. A.; Microchem. J. 2013, 109, 145.

10. Dehelean, A.; Magdas, D. A.; Sci. World J. 2013, 2013, DOI $10.1155 / 2013 / 215423$.

11. Lo Dico, G. M.; Galvano, F.; Dugo, G.; D’ascenzi, C.; Macaluso, A.; Vella, A.; Giangrosso, G.; Cammilleri, G.; Ferrantelli, V.; Food Chem. 2018, 245, 1163.

12. Bezerra, M. A.; Ferreira, S. L. C.; Novaes, C. G.; dos Santos, A. M. P.; Valasques, G. S.; Cerqueira, U. M. F. M.; Alves, J. P. S.; Talanta 2019, 194, 941.

13. Feist, B.; Mikula, B.; Food Chem. 2014, 147, 302.

14. Li, F.; Yu, Z.; Han, X.; Lai, R. Y.; Anal. Chim. Acta 2019, 1051, 1.

15. Li, B.; Hu, J.-y.; Zhao, M.-t.; J. Chin. Mass Spectrom. Soc. 2010, 31,1

16. Ellison, S. L. R.; Thompson, M.; Analyst 2008, 133, 992.

17. Kelly, W. R.; MacDonald, B. S.; Guthrie, W. F.; Anal. Chem. 2008, 80, 6154 .

18. Wood, S.; Botha, A.; The New ISO Guide 80: Guidance for the in-house Preparation of Quality Control Materials (QCMs); available at https://www.iso.org/standard/44313.html, accessed on January 28, 2020.

19. SANTE/11813/2017: Guidance Document on Analytical Quality Control and Method Validation Procedures for Pesticide Residues and Analysis in Food and Feed; European Commission, 2017. Available at https://ec.europa.eu/food/sites/food/files/ plant/docs/pesticides_mrl_guidelines_wrkdoc_2017-11813. pdf, accessed in January 2020.

20. Bohm, D. A.; Stachel, C. S.; Hackenberg, R.; Gowik, P.; Anal. Chim. Acta 2011, 700, 58.

21. Food and Drug Administration (FDA); Analytical Procedures and Methods Validation for Drugs and Biologics Guidance for Industry; 2015, available at https://www.fda.gov/media/87801/ download, accessed in January, 2020.

22. https://www.iso.org/standard/60281.html, accessed in January 2020.
23. AOAC Official Method 2015.01: Heavy Metals in Food; AOAC: Arlington, USA, 2015.

24. Hauswaldt, A. L.; Rienitz, O.; Jährling, R.; Fischer, N.; Schiel, D.; Labarraque, G.; Magnusson, B.; Accredit. Qual. Assur. 2012, 17, 129.

25. Codex Alimentarius; General Standard for Contaminants and Toxins in Food and Feed, CODEX STAN 193-1995; FAO/WHO: Rome, 1995.

26. Harrington, C. F.; Merson, S. A.; D’Silva, T. M.; Anal. Chim. Acta 2004, 505, 247.

27. Horwitz, W.; Anal. Chem. 1982, 54, 67A.

28. González, A. G.; Herrador, M. Á.; Asuero, A. G.; Talanta 2010, 82, 1995.

29. National Institute of Standards and Technology (NIST); SRM Order Request System; available at https://www-s.nist.gov/ srmors/view_cert.cfm?srm=1515, accessed on January 27, 2020.

30. R Development Core Team; RStudio, R: A Language and Environment for Statistical Computing; The R Foundation for Statistical Computing, Vienna, Austria, 2014.

31. Li, Y.; Chen, C.; Li, B.; Sun, J.; Wang, J.; Gao, Y.; Zhao, Y.; Chai, Z.; J. Anal. At. Spectrom. 2006, 21, 94.

32. Astolfi, M. L.; Marconi, E.; Protano, C.; Vitali, M.; Schiavi, E.; Mastromarino, P.; Canepari, S.; Anal. Chim. Acta 2018, 1040, 49.

33. Horwitz, W.; Albert, R.; J. AOAC Int. 2006, 89, 1095.

34. Ahumada F., D. A.; Rodríguez L., D.; Zamudio S., A.; Mojica C., A.; Rev. Colomb. Quim. 2012, 41, 227.

35. Van Der Veen, A. M. H.; Pauwels, J.; Accredit. Qual. Assur. 2000, 5,464 .

36. Marín B., E.; Lemus M., R.; Flores M., V.; Vega G., A.; Rev. Chil. Nutr. 2006, 33, DOI 10.4067/S0717-75182006000500009.

37. Inagaki, K.; Narukawa, T.; Hioki, A.; Miyashita, S.; Long, S. E.; Ellisor, M. B.; Peng, S. L.; Dewi, F.; Shin, R.; Kapp, T.; Wai-hong, F.; Hei-shing, C.; Chao, W.; Kaewkhomdee, N.; Taebunpakul, S.; Thiengmanee, U.; Yafa, C.; Metrologia 2017, 54, DOI 10.1088/0026-1394/54/1A/08021.

38. NIM CCQM-K145: Toxic and Essential Elements in Bovine Liver Powder, available at https://www.bipm.org/kcdb/ comparison?id=496, accessed on January 27, 2020.

39. Briche, C. S. J. W.; Holcombe, G.; Sargent, M.; Metrologia 2006, 43, 08014 